\title{
Knowledge and risk factors for stroke among undergraduates in southwestern Nigeria
}

\author{
Wasiu Olalekan Adebimpe, PhD'
}

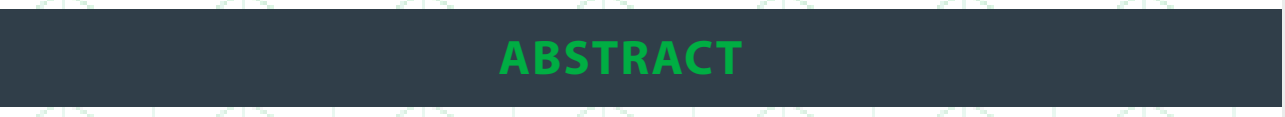

The burden of noncommunicable diseases due to stroke is increasing. Despite this, community-based studies that could stimulate stroke primordial prevention among the population at risk are sparse. This study assessed community knowledge and risk factors of stroke among university undergraduates in Osogbo, southwestern Nigeria. A descriptive cross-sectional study was conducted among 420 male undergraduates selected through multi-stage sampling method. Research instruments were selfadministered semi structured questionnaires. Data was analyzed using the SPSS software version 17.0. Four hundred and seven (96.9\%) have heard about stroke. Good mean knowledge score of causes, symptoms, warning signs and risk factors of stroke were $62.6 \%, 61.7 \%$ and $42.1 \%$ and $56.7 \%$ respectively. Three hundred and nine (75.9\%) said the body part primarily affected by stroke was the brain, while $35(8.6 \%)$ said it was the kidneys. Only 73 (17.9\%) perceived that they were at risk of stroke while 33 $(8.1 \%)$ said they could not have stroke. Single risk was found among $43(10.2 \%)$, double risk among $334(79.5 \%)$ and multiple (>2) risks among $43(10.2 \%)$ of respondents. Predictors of good knowledge of risk factors among respondents found on multivariate analysis were older age, having one or both parents who had stroke in the past, smoking cigarettes, and having multiple risk factors of stroke. It was concluded that respondents had good awareness and relatively good knowledge of causes, symptoms and risk factors of stroke; however, respondents had poor knowledge of warning signs. Sustained public awareness could bridge existing gap among respondents towards primordial stroke prevention.
Author affiliations are listed at the end of this article.

Correspondence to: Olalekan Adebimpe, PhD University of Medical Sciences lekanadebimpe@gmail.com

\section{KEYWORDS}

Stroke, Undergraduates, Risk factors, Knowledge, Osogbo

\section{INTRODUCTION}

The epidemiological transition from communicable to noncommunicable diseases (NCD) has been recognized over several decades. Increased predisposition to western lifestyles and uncontrolled urbanization had been reported as some of the reasons. Diseases such as stroke, diabetes and hypertension are now on the rise. 1 Stroke is a noncommunicable disease of public health importance that causes deaths and disability worldwide, and Nigeria is not an exception to this trend. Though a rural study in southwestern Nigeria puts the crude prevalence of stroke at 0.58 per
1,000 population, ${ }^{2}$ community-based studies on the prevalence, knowledge and attitude of sub-Saharan Africans associated with stroke risk factors are sparse. Outcomes of primordial preventive efforts against stroke and other NCDs would depend on the extent and pattern of awareness of modifiable risk factors, warning signs, and knowledge and attitude of the vulnerable groups to the disease. Common known risk factors for stroke include hypertension, high cholesterol diet, diabetes, heart disease and smoking. These risk factors for stroke are controllable and preventable. However, public awareness of stroke is generally low. ${ }^{3}$ The changing epidemiology of hypertension and stroke, most specifically the age 
of onset, has reduced over the years and is putting youth at greater risk.

In order to facilitate health interventions that would reduce mortality and morbidity due to stroke, it is important to assess public awareness about the disease and its risk factors most especially among the younger population who are still amenable to primordial and primary prevention. This study assessed community knowledge and risk factors of stroke among university undergraduates in Osogbo, southwestern Nigeria.

\section{METHODS}

\section{Study Area}

Osogbo, the capital city of Osun state in southwestern Nigeria, has a total population of about 450,000 according to a recent projection of the 2006 national population census. ${ }^{4}$ The prevalence of stroke in the general population was not known. The general traditional belief was that stroke occurs as a result of excessive thinking and sins against God. There is a teaching and a general hospital in the city. There are three tertiary institutions which include LAUTECH College of Health Sciences, the Fountain University (which is privately owned) and the Osun State University.

\section{STUDY POPULATION}

Study population consisted of male students who are currently enrolled as full time students in selected tertiary institutions.

\section{StUdY DESIGN}

This was a descriptive cross-sectional study.

\section{SAMPLE Size estimation}

Using the Leslie Kish formula (for the calculation of sample size for population less than 10,000 as modified) 5 and prevalence rate of $0.58,2$ a sample size of 374 was calculated. This was increased to 400 to take care of attrition and non-response in the study.
SAMPLING

A multi-stage sampling method was adopted. In Stage I, two out of three institutions were selected at random using simple balloting. Questionnaires were equally allocated to both institutions. In an institution in Stage 2, two academic levels out of four (most students do a four-year course) were randomly selected, employing simple balloting. The same technique was used in selecting a course or class from each selected academic level in Stage 3. In a class (Stage 4), a systematic random sampling of one in three students as they sat in the class preparing for a lecture on the day of data collection was drawn. Questionnaires were administered until the number of questionnaire allocated for that class got exhausted. In case the number was not exhausted in a class, another class or course was randomly selected and the procedure repeated for subject selection.

RESEARCH INSTRUMENTS

Research instrument was a semi structured and pre-tested self-administered questionnaire supervised by two trained nurse assistants in each of the institutions. Study variables included socio-demographic characteristics, awareness and knowledge of warning signs, symptoms and risk factors of stroke. The pretesting was carried out by administering the questionnaires on twenty students of the University of Ibadan in neighboring Oyo State. Feedback received from respondents on the questionnaire was used to make corrections to the questionnaire before the original research data collection.

\section{ETHICAL CLEARANCE}

Ethical clearance to conduct the study was obtained from LAUTECH Teaching Hospital ethical review committee. Further permission was obtained from the dean of selected faculty and heads of departments whose students were selected for the study.

DATA MANAGEMENT

Data was entered into the SPSS software version 
17.0 and validated through double entry and manual random checks. Frequency tables and charts were generated. Knowledge aggregate score was calculated based on the allocated number of questions; a correct answer attracted +1 mark while an incorrect answer attracted 0 mark. Scores below the average score were regarded as poor knowledge scores; scores above the average were good knowledge scores. Single and double risk were eventually re-categorized as 'low' while multiple risks (risks >3) were re-categorized as 'high' risk. The chi squared test was employed in bi-variate analysis. A multivariate analysis using the binary logistic regression model was carried out using some selected variables against the major outcome variables. $P$ values were considered significant at values $<0.05$ for all inferential statistics.

\section{RESULTS}

Table 1 shows: mean age of respondents was $21.5+3.4$ years, all were males, the 200 and 300 level classes constituted $161(38.3 \%)$ and 163 (38.8\%) respectively, 284 (67.6\%) were Christians, while 387 $(91.2 \%)$ were single.

Table 2 shows the awareness and general knowledge about stroke. 407 (96.9\%) have heard about stroke; the major source of information was tv/radio for 160 (39.3\%) and health care workers for 110 (26.3\%). About 287 (67.3\%) could readily describe or define stroke; 334 (82.1\%) described it as a noncommunicable disease, while 132 (32.4\%) believed that stroke was uncommon.

Table 3 shows the knowledge of risk factors of stroke. The parents of $104(25.6 \%)$ and 65 (16.0\%) of the respondents were reported to have past history of high blood pressure and stroke respectively. Common complications of stroke known to the respondents include mortality 342 (84.0\%), heart failure 272 (66.8\%) and kidney disease 149 (36.6\%).

Figure 1 shows mean knowledge scores of some parameters concerning stroke. Good mean knowledge score of causes, symptoms, warning signs and risk factors of stroke were $62.6 \%, 61.7 \%$. $42.1 \%$ and $56.7 \%$ respectively. Three hundred and nine $(75.9 \%)$ said the body part primarily affected by stroke was the brain, while $35(8.6 \%)$ said it was the kidneys. Only 73 (17.9\%) believed that they were at risk of stroke while $33(8.1 \%)$ said they could not have stroke. Considering consumption of table salt as a possible risk factor, only 18 (4.4\%) said their salt intake was excessive or heavy while 281 (69.0\%) admitted very low salt intake. Only 168 (41.3\%) ever

\begin{tabular}{|c|c|c|}
\hline Variable & $\mathbf{N}$ & $\%$ \\
\hline \multicolumn{3}{|l|}{ Age (mean $21.5+3.4$ years) } \\
\hline $15-19$ & 113 & 26.9 \\
\hline $20-24$ & 239 & 56.9 \\
\hline $25-29$ & 62 & 14.8 \\
\hline$>30$ & 6 & 1.4 \\
\hline \multicolumn{3}{|l|}{ Level } \\
\hline 100 & 41 & 9.8 \\
\hline 200 & 161 & 38.3 \\
\hline 300 & 163 & 38.8 \\
\hline 400 & 49 & 11.7 \\
\hline Others & 6 & 1.4 \\
\hline \multicolumn{3}{|l|}{ Religion } \\
\hline Christianity & 284 & 67.6 \\
\hline Islamic & 115 & 27.4 \\
\hline Traditional & 21 & 5.0 \\
\hline Others & & \\
\hline \multicolumn{3}{|l|}{ Marital status } \\
\hline Single & 387 & 92.1 \\
\hline Currently married & 23 & 5.5 \\
\hline Divorced/separated/widowed & 10 & 2.4 \\
\hline
\end{tabular}

TABLE 1: Socio-demographic data of respondents checked their blood pressure, $23(5.7 \%)$ ever checked their blood sugar level, while 306 (75.2\%) believed that stroke can be diagnosed and treated.

Figure 2 shows the pattern of risk of stroke in relation to the following predisposing factors: smoking, alcohol intake, past family history of hypertension or stroke, consumption of western/high 


\begin{tabular}{|c|c|c|}
\hline Variable & $\mathrm{F}$ & $\%$ \\
\hline \multicolumn{3}{|l|}{ Have you heard about stroke } \\
\hline Yes & 407 & 96.9 \\
\hline No & 13 & 3.1 \\
\hline \multicolumn{3}{|l|}{ Sources of information $(n=407)$} \\
\hline TV/Radio & 160 & 39.3 \\
\hline Newspaper/textbook & 11 & 2.7 \\
\hline Internet & 92 & 22.6 \\
\hline Health care workers & 107 & 26.3 \\
\hline Others & 37 & 9.1 \\
\hline \multicolumn{3}{|l|}{ Basic knowledge of stroke (yes option) } \\
\hline Could describe stroke & 287 & 68.3 \\
\hline Stroke is uncommon & 132 & 32.4 \\
\hline It is not a communicable disease & 334 & 82.1 \\
\hline Have ever seen someone with stroke & 297 & 73.0 \\
\hline Stroke can be diagnosed and treated & 306 & 75.2 \\
\hline \multicolumn{3}{|l|}{ Knowledge of symptoms or signs of stroke } \\
\hline Weakness in the arms or upper limb & 164 & 40.3 \\
\hline Weakness in the legs or lower limbs & 55 & 13.5 \\
\hline Inability to urinate or defecate & 26 & 6.4 \\
\hline Inability to speak & 30 & 7.4 \\
\hline Losing consciousness & 6 & 1.5 \\
\hline Both sides of the body affected & 34 & 8.4 \\
\hline Only one side of the body is affected & 56 & 13.8 \\
\hline \multicolumn{3}{|l|}{ Knowledge of leading causes of stroke } \\
\hline High blood pressure & 259 & 61.7 \\
\hline Diabetes & 36 & 8.6 \\
\hline RTA/trauma & 24 & 5.7 \\
\hline Obesity/high cholesterol & 164 & 40.3 \\
\hline Excessive thinking & 57 & 13.6 \\
\hline Epilepsy & 11 & 2.6 \\
\hline Others e.g. smoking & 14 & 3.3 \\
\hline \multicolumn{3}{|l|}{ Body part/organ primarily affected by stroke are } \\
\hline Kidneys & 35 & 8.6 \\
\hline Brain & 309 & 75.9 \\
\hline Heart & 63 & 15.5 \\
\hline \multicolumn{3}{|l|}{ Knowledge of Warning signs } \\
\hline Numbness in the limbs & 117 & 43.5 \\
\hline Sudden headache & 35 & 8.6 \\
\hline Sudden loss of balance & 100 & 24.6 \\
\hline Sudden difficulty with seeing or speaking or sleeping & 71 & 17.4 \\
\hline Others & 24 & 5.9 \\
\hline
\end{tabular}

TABLE 2: Knowledge about warning signs and causes of stroke

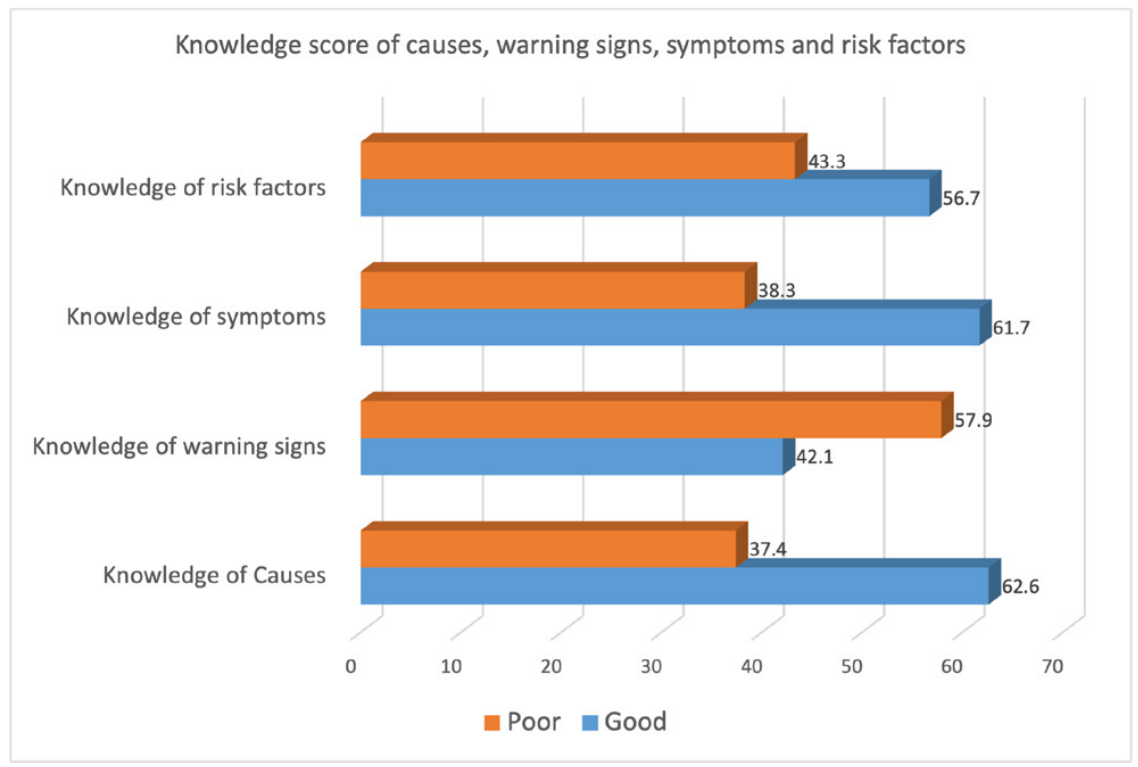

FIGURE 1: Knowledge score of causes, warning signs, symptoms and risk factors 


\begin{tabular}{|c|c|c|}
\hline Variable & $\mathrm{F}$ & $\%$ \\
\hline \multicolumn{3}{|l|}{ Known risk factors (yes option) } \\
\hline Old age & 305 & 74.9 \\
\hline Being a male & 60 & 14.7 \\
\hline Having hypertension & 336 & 82.6 \\
\hline Being fat or having high cholesterol & 174 & 42.8 \\
\hline Having diabetes & 146 & 35.9 \\
\hline Cigarette smoking & 110 & 27.0 \\
\hline Having a family member having stroke & 40 & 9.8 \\
\hline \multicolumn{3}{|l|}{$\begin{array}{l}\text { One or both parents reportedly had the following health } \\
\text { problems (yes option) }\end{array}$} \\
\hline High blood pressure & 104 & 25.6 \\
\hline Stroke in the past & 65 & 16.0 \\
\hline \multicolumn{3}{|l|}{ Complication of stroke (yes option) } \\
\hline Can kill & 342 & 84.0 \\
\hline Heart failure & 272 & 66.8 \\
\hline Kidney disease & 149 & 36.6 \\
\hline \multicolumn{3}{|l|}{ Do you think that you are at risk of having stroke } \\
\hline Yes & 73 & 17.9 \\
\hline No & 248 & 60.9 \\
\hline Don't know/no response & 86 & 21.2 \\
\hline \multicolumn{3}{|l|}{ Do you think you can have stroke } \\
\hline Yes & 33 & 8.1 \\
\hline No & 345 & 84.8 \\
\hline Don't know/no response & 29 & 7.1 \\
\hline \multicolumn{3}{|l|}{ Alcohol (yes option) } \\
\hline Have you ever taken alcohol & 238 & 58.5 \\
\hline Still takes alcohol & 160 & 39.3 \\
\hline \multicolumn{3}{|l|}{ Smoking (yes option only) } \\
\hline Have you ever taken cigarette & 65 & 16.0 \\
\hline Still smokes & 32 & 7.9 \\
\hline \multicolumn{3}{|l|}{ What is your pattern of table salt intake like } \\
\hline Excessive or heavy & 18 & 4.4 \\
\hline I spray food with salt & 57 & 14.0 \\
\hline I don't spray cooked food with salt & 51 & 12.5 \\
\hline Very low salt intake & 281 & 69.0 \\
\hline \multicolumn{3}{|l|}{ Other basic knowledge about stroke (Yes options only) } \\
\hline Often take food from eateries like Mr. Biggs & 226 & 55.5 \\
\hline Regularly eat food like egg, margarine, butter, cheese & 242 & 59.5 \\
\hline I do daily exercises & 235 & 57.5 \\
\hline Ever checked your blood pressure & 168 & 41.3 \\
\hline Ever checked your blood sugar level & 23 & 5.7 \\
\hline
\end{tabular}

TABLE 3: Knowledge of risk factors of stroke

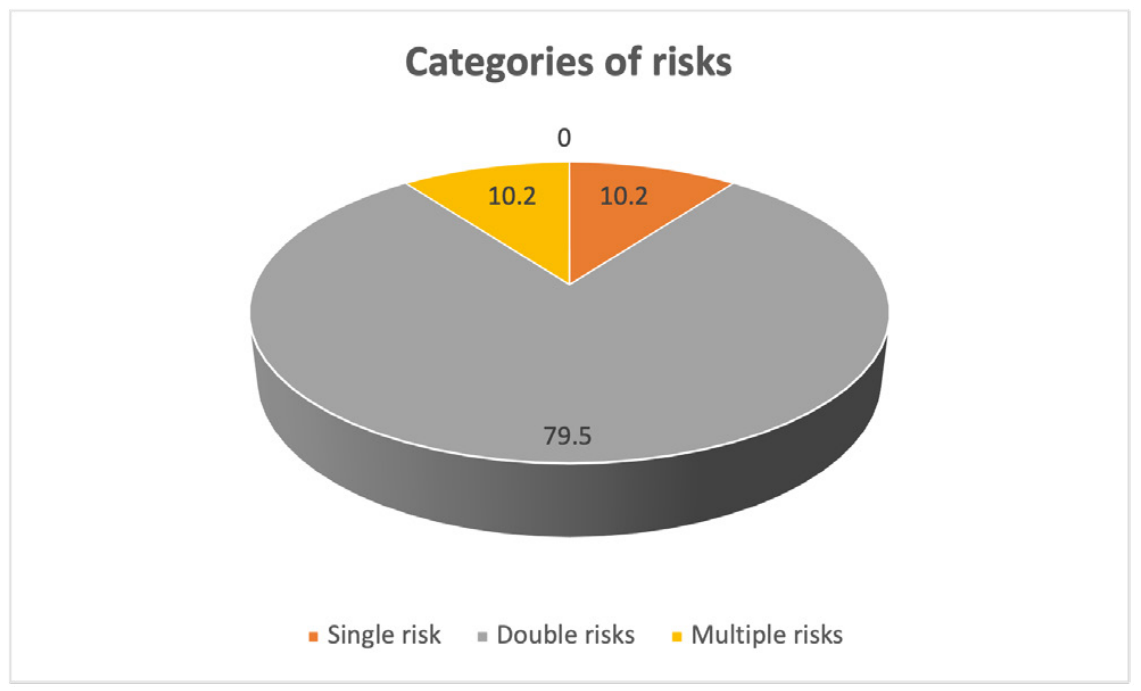

FIGURE 2: Categories of risks 


\begin{tabular}{|c|c|c|c|c|}
\hline \multicolumn{5}{|l|}{ Bi-variate analysis } \\
\hline & \multicolumn{2}{|c|}{ Aware of stroke } & \multirow[t]{2}{*}{$\mathrm{X}^{2}$} & \multirow[t]{2}{*}{$\mathrm{P}$} \\
\hline & Yes & No & & \\
\hline $\begin{array}{l}\text { Knowledge score of warning signs } \\
\text { Good } \\
\text { Poor }\end{array}$ & $\begin{array}{l}166(93.8) \\
241(99.2)\end{array}$ & $\begin{array}{l}11(6.2) \\
2(0.8)\end{array}$ & 9.925 & 0.002 \\
\hline $\begin{array}{l}\text { Knowledge of causes } \\
\text { Good } \\
\text { Poor }\end{array}$ & $\begin{array}{l}259(98.5) \\
148(94.3)\end{array}$ & $\begin{array}{l}4(1.5) \\
9(5.7)\end{array}$ & 5.814 & 0.016 \\
\hline $\begin{array}{l}\text { Knowledge of risk factors } \\
\text { Good } \\
\text { Poor }\end{array}$ & $\begin{array}{l}236(99.2) \\
171(94.0)\end{array}$ & $\begin{array}{l}2(0.8) \\
11(6.0)\end{array}$ & 9.310 & 0.002 \\
\hline $\begin{array}{l}\text { Knowledge of symptoms } \\
\text { Good } \\
\text { Poor }\end{array}$ & $\begin{array}{l}253(97.7) \\
154(95.7)\end{array}$ & $\begin{array}{l}6(2.3) \\
7(4.3)\end{array}$ & 1.366 & 0.243 \\
\hline $\begin{array}{l}\text { Risk categories } \\
\text { Single } \\
\text { Double } \\
\text { Multiple }\end{array}$ & $\begin{array}{l}36(83.7) \\
328(98.2) \\
43(100)\end{array}$ & $\begin{array}{l}7(16.3) \\
6(1.8) \\
0(0.0)\end{array}$ & 28.170 & 0.001 \\
\hline $\begin{array}{l}\text { Do you think that you are at risk } \\
\text { Yes } \\
\text { No }\end{array}$ & $\begin{array}{l}82(98.8) \\
325(96.4)\end{array}$ & $\begin{array}{l}1(1.2) \\
12(3.6)\end{array}$ & 5.972 & 0.050 \\
\hline \multicolumn{5}{|c|}{ Binary logistics regression (Good knowledge of risk factors of stroke) } \\
\hline & OR & $95 \% \mathrm{CI}$ & & P value \\
\hline & & Lower & Upper & \\
\hline Age $(($ Reference category $=15-19$ years $)$ & 1.74 & 1.281 & 2.363 & 0.001 \\
\hline $\begin{array}{l}\text { One or both parents having stroke in the } \\
\text { past (Reference category=No }\end{array}$ & 1.80 & 0.160 & 2.239 & 0.633 \\
\hline Smoking (Reference category $=$ No) & 1.71 & 1.011 & 2.877 & 0.045 \\
\hline Taking alcohol (Reference category $=$ No) & 0.94 & 0.227 & 1.063 & 0.071 \\
\hline $\begin{array}{l}\text { Taking daily exercises (Reference } \\
\text { category=No) }\end{array}$ & 1.054 & 0.640 & 1.735 & 0.837 \\
\hline $\begin{array}{l}\text { Risk categories (Reference } \\
\text { category=multiple risk) }\end{array}$ & 0.41 & 0.256 & 0.654 & 0.001 \\
\hline
\end{tabular}

TABLE 4: Association between awareness, knowledge of risk factors of stroke and some selected variables

cholesterol diet. Single risk was found among 43 (10.2\%), double risk among 334 (79.5\%) and multiple (more than double risk) among 43 (10.2\%) of respondents.

In Table 4, a statistically significant association was found between awareness of stroke and risk categories, believing that one is at risk, and all the four knowledge scores (except the mean knowledge of symptom) with $\mathrm{P}<0.05$ on bi-variate analysis. On multivariate analysis using binary logistic regression model, respondents who were older than 19 years (non-adolescents) were 1.7 times more likely to have good knowledge of risk factors compared to adolescents 15-19 years and this observation was statistically significant. (OR $1.74,95 \% \mathrm{Cl} 1.281-2.363$, P-0.001). Respondents whose one or both parents had stroke in the past were 1.8 times more likely to have good knowledge score of stroke compared to those whose parents did not, though this observation was not found to be statistically significant (OR 1.8, $95 \% \mathrm{Cl} 0.160-2.239$ and $\mathrm{P}-0.633)$.

Respondents who were smokers were 1.7 times more likely to have good knowledge of risk factors compared to nonsmokers and this observation was found to be statistically significant (OR 1.71, 95\%Cl 1.011-2.877 and P-0.045). There was no difference in comparison of knowledge of risk factors among those taking alcohol and those not taking alcohol and among those who did daily exercise and those who did not; these two observations were both not statistically significant (P- 0.071 and 0.837 respectively). However, respondents with single risk were 2.5 times less likely to have good knowledge of risk factors compared to those with multiple risks and this observation was found to be statistically significant (OR $0.41,95 \% \mathrm{Cl} 0.256-0.654)$. Thus, predictors of good knowledge of risk factors among respondents were: older age, parents who had stroke in the past, cigarette smoking, and having multiple risk factors of stroke.

\section{DISCUSSIONS}

\section{SOCIO-DEMOGRAPHIC CHARACTERISTICS}

Stroke, also referred to as cardiovascular accident, is a sudden neurologic deficit manifesting either as vascular occlusion from thrombosis or embolism or from hemorrhage into the brain due to a blood vessel rupture usually due to hypertension. ${ }^{6}$ The major source of awareness about stroke in this study was tv/radio; this is in agreement with similar studies reporting the usefulness and relevance of the mass media in improving public awareness about noncommunicable diseases as well as their warning signs. ${ }^{7,8}$ The radio and tv are accessible 
and affordable to most households in Nigeria, and they have been a veritable means of disseminating information on health matters.

A statistically significant relationship was found between age of our respondents and awareness of stroke. This finding disagreed with a study which indicates no significant relationship between the awareness level of stroke and age and educational level of their respondents. ${ }^{9}$ Compared to the younger ones, older students are more likely to have read books on stroke, more likely to have had lectures on topics related to stroke, and more likely to have also seen a stroke patient (based on personal experience which is expected to rise with age).

\section{KNOWLEDGE OF RISK FACTORS}

Regarding knowledge of risk factors, a little above half of our respondents had good mean knowledge score. This is better compared to study by Pandian et al in which about two-thirds of the participants had poor knowledge of risk factors ${ }^{10}$. This poor knowledge pattern was also supported by several other studies. ${ }^{11-13}$ Awareness and good knowledge of stroke risk factors could encourage better attitude towards weight reduction messages, obesity and hypertension. Poor awareness and knowledge is an indication that better awareness programs are needed, to implement weight reduction strategies targeting this vulnerable population and encourage behavioral modification toward primordial, primary and secondary prevention.

The commonly identified stroke risk factors known to majority of our respondents were hypertension, stress, hypercholesterolemia, smoking and obesity; this is in agreement with other studies. ${ }^{10,14,15}$ In a study by Mississippi State Department of Health, only one-fifth of the respondents indicated high cholesterol and cigarette smoking as stroke risk factors. ${ }^{16}$ Knowledge of a disease could be a pointer to the preparedness of the patient in seeking help and his or her attitude toward prevention efforts. These patterns of knowledge of causes, risk factors and warning signs call for the improvement of the awareness level for stroke, including risk reduction activities.
KNOWLEDGE OF WARNING SIGNS/SYMPTOMS In this study, nearly three-fifth of respondents had poor mean knowledge of warning signs of stroke, with the highest known warning sign being numbness in the limbs (known by a little less than half of respondents). Other warning signs were known among far fewer number of respondents, thus suggesting an overall poor knowledge of warning signs. Sallar et al reported much lower good knowledge scores: $21.6 \%$ could name one warning sign and $11.7 \%$ could name two warning signs. ${ }^{17}$ The poor level of awareness of stroke warning signs relative to risk factors was consistent with two previous reports.18,19 However, higher knowledge figures were reported from Johnston et al in which three quarter and three-fifth of respondents, respectively, were able to select correctly the first and second warning signs of stroke. ${ }^{20}$

About three quarter of our respondents knew someone who had stroke before, in agreement with study by Johnston et al that reported two-thirds. 20 Likewise, three quarter of our respondents opined that brain is the body part being affected by stroke; this agrees with study by Nicol et al. ${ }^{9}$

\section{SYMPTOMS OF STROKE}

In our study, a little less than one third identified five of the listed symptoms of stroke, and the weakness of the arms or upper limb was the most known symptom. This is in agreement with a study by Nicol et al in which only one quarter of respondents identified all five symptoms. ${ }^{9}$ In study by Hickey et $\mathrm{al}^{3}{ }^{3}$ less than half of the population identified these established warning signs (with the exception of slurred speech). Low and middle-income countries including Nigeria have been found to account for over $87 \%$ disability adjusted life years (DALYs) from stroke; ${ }^{20}$ this calls for a need to step up awareness improvement efforts among stakeholders involved in prevention of noncommunicable diseases in Nigeria.

This study has opened up opportunities for evidence based primordial and primary prevention of hypertension and stroke since it was carried out among the young population who are not yet 
affected but vulnerable to developing hypertension and stroke. Future studies may wish to consider and compare findings in both sexes and include a direct measure of blood pressure in order to determine prevalence of hypertension, which is the major risk factor for stroke in this study area. In conclusion, poor knowledge of warning signs and poor risk perception of stroke were found among studied respondents, amidst significant risk factors. The need to increase public awareness of stroke risk factors and warning signs is thus important in addressing the identified gaps in knowledge and promotion of primary and secondary prevention strategies among the young population studied.

\section{AUTHOR AFFILIATIONS}

1. University of Medical Sciences, Ondo, Nigeria

\section{REFERENCES}

1. World Health Organization. Non-communicable diseases Fact sheet Updated January 2015 Geneva, Switzerland: World Health Organization. 2015. Accessed on 08thFebruary 2016. Available at: http://www.who.int/mediacentre/factsheets/ fs355/en/

2. Osuntokun BO, Daija AO, Schoenberg BS. Neurological disorders in Nigerian Africans: a community based study. ActaNeurol Scand. 1987;75:13-21.

3. Hickey A, O'Hanlon A, McGee H, Donnellan C, Shelley E, Horgan F et al. Stroke awareness in the general population: knowledge of stroke risk factors and warning signs in older adults. BMC Geriatrics. 2009;9:35.

4. National Population Commission. The 2006 National Census preliminary results. NPC Abuja Nigeria 2006.

5. Araoye MO. Research methodology with statistics for health and social sciences. Ilorin, Nigeria: Nathadex Publishers. 2004:117-120.

6. Stroebele N, Muller-Riemenschneider F, Nolte $\mathrm{CH}$, Muller-Nordhorn J, Bockelbrink A, Willich SN. Knowledge of risk factors, and warning signs of stroke: A systematic review from a gender perspective. International Journal of Stroke. 2011;6(1):60-6.
7. Reeves MJ, Rafferty AP, Aranha AAR, Theisen V. Changes in knowledge of stroke risk factors and warning signs among Michigan adults. Cerebrovasc Dis. 2008;25:385-391.

8. Agyemang $C$, van Valkengoed I, Koopmans $R$, Stronks K. Factors associated with hypertension awareness, treatment and control among ethnic groups in Amsterdam, The Netherlands: the SUNSET study. J Hum Hypertens. 2006;20:874-81.

9. Nicol MB and Thrift AG. Knowledge of risk factors and warning signs of stroke. Vasc Health Risk Manag. 2005;1(2):137-147.

10. Pandian JD, Jaison A, Deepak SS. Public awareness of warning symptoms, risk factors, and treatment of stroke in Northwest India. Stroke 2005;36:644-8.

11. Yoon SS, Byles J. Perceptions of stroke in the general public and patients with stroke: a qualitative study. BMJ. 2002;324:1065-1070.

12. Miller JE. Knowledge of stroke risk factors, symptoms, and treatment among New Jersey adults. N J Med. 2001;98:47-53.

13. Pancioli AM, Broderick J, Kothari R. Public perception of stroke warning signs and knowledge of potential risk factors. JAMA. 1998;279:1288-92.

14. Milner A, Lewis WJ, Ellis C. Knowledge of stroke risk factors and early warning signs of stroke among students enrolled in allied health programs: a pilot study. J Allied Health. 2008;37(4):e296-315.

15. Kamran S, Bener AB, Deleu D. The level of awareness of stroke risk factors and symptoms in the Gulf Cooperation Council Countries: Gulf cooperation council stroke awareness study. Neuroepidemiology. 2007;29:235-42.

16. Mississippi State Department of Health (MSDH, 2005). Available Online at http:// www.msdh.state.ms.us/msdsite/index. cfm/43,1842,297,63,pdf/StrokeRe- port2005. Accessed January 15th 2016.

17. Sallar AM, Williams PB, Omishakin AM, Lloyd DP. Stroke prevention: awareness of risk factors for stroke among African American residents in the Mississippi delta region. Journal of the National Medical Association. 2010;102(2):85.

18. Reeves MJ, Hogan JG, Rafferty AP. Knowledge of stroke risk factors and warning signs among Michigan adults. Neurology. 2002;59:1547-1552. 19. Schneider AT, Pancioli AP, Khoury JC, 
Rademacher E, Tuchfarber A, Miller R et al. Trends in community knowledge of the warning signs and risk factors for stroke. JAMA. 2003;289:343-6.

20. Johnston SC, Mendis S, Mathers CD. Global variation in stroke burden and mortality: estimates from monitoring, surveillance, and modelling. Lancet Neurol. 2009;8:345-354. 